\title{
GAEC cross compliance standard Vegetation buffer on water courses: possible methods of detection by Remote Sensing products and existing data
}

\author{
Paolo Tosi, Livio Rossi \\ SIN-AGEA, National Informative System for Agriculture/National Payment Agency in agriculture, \\ Roma, Italy
}

\section{Abstract}

The Agency for Agricultural Payments National Payment Agency (AGEA) in Italy, in order to manage and control EU farmer subsidies in Agriculture, is supported by SIN, an owned public/private company, aiming at facing technical solutions and innovation developments.

Since 2005 SIN-AGEA have been testing and performing innovation tools and methods, especially in CAP cross compliance application. A vegetation buffer strip is requested, flanking pre-defined water streams, by Reg. EC 73/2009, CAP cross compliance policies, with pertinence from 2012. Due to the existing collaboration agreement JRCAGEA-SIN, and the Rete Rurale Nazionale, tests and feasibility have been started to:

- improve the knowledge of cross compliance;

- identify feasible farmer obligations and clear rules of behaviour;

- develop updated controls methods;

- integrate available territorial information, creating awareness and user connection

The paper faces criteria definition for water streams identification, application areas, different risk zones, buffer width, efficiency indicators, through: existing data, new Remote Sensing (RS) products and GIS tools for watersheds characterization. A shared decision, both for methodology and homogeneous farmer commitments at national/EU level, using validated layers/data set, at contained costs, is the main target.

Correspondence: Paolo Tosi, SIN srl Sistema Informativo Nazionale per lo sviluppo dell'agricoltura, via Salandra 13, 00187 Roma, Italy.

Tel. +39.06.44490422. E-mail: paolo.tosi@sin.it

Key words: cross compliance, GAEC, standard, buffer strips, water pollution, GIS, remote sensing.

Acknowledgements: the study is promoted by the Ministry of Agricultural, Alimentation and Forestry Policy and it is guided and monitored by the Mars Staff of the Joint Research Centre of the European Commission.

Received for publication: 25 March 2011.

Accepted for publication: 18 May 2011.

CC Copyright P. Tosi and L. Rossi., 2011

Under no circumstances figures can be used without prior written consent of the copyright owner.

Licensee PAGEPress, Italy

Italian Journal of Agronomy 2011; 6(s1):e18

doi:10.4081/ija.2011.6.s1.e18

This work is licensed under a Creative Commons Attribution NonCommercial 3.0 License (CC BY-NC 3.0).

\section{Introduction}

The Agency for Agricultural Payments in Italy AGEA, is assisted by SIN (a private/public company, established after an international tender) for any issue in managing and controlling EU CAP farmer subsidies. SIN provides AGEA and the EU Offices with both operational/technical activities and innovation solutions. One of the most important theme regards the CAP cross compliance application and control, due to its intrinsic complexity and its wide territorial relationships. The following summary fits the above mentioned issue.

The establishment of buffer strips along water courses to protect them against pollution and run-off (USDA-NRCS/USEPA, 2000) is a forthcoming cross compliance requirement for farmers who receive payments under several aid schemes of the Common Agricultural Policy (CAP).

The requirement is part of the $5^{\text {th }}$ issue, Protection and management of water, of the Good Agricultural and Environmental Conditions (GAEC), as in art. 6 of Reg. (EC) 73/2009.

The target of the research activity is, first of all, the definition of a requirement applicable to farm level, that must clearly be put into practise and controlled. The second purpose of the study is to refer the requirement to the agro-environment, such as that: i) it can be represented on a map and/or on GIS; ii) its application is different/graduated, in relationship with water courses vulnerability parameters and in terms of risk factors or water courses pollution variation (Ongley, 1996); iii) it is possible to exclude the requirement application to water courses segments, due to both agricultural land use or management conditions and natural protection of some water courses (Vianello et al., 2005).

The test, still in progress, involves a multi-factor framework, able to take into account the extreme variability of the parameters, which concur to achieve the target. The data system is able to adapt the requirement and the land/ water policy to the changes of the agricultural context, giving the base for a monitoring and programming tool, useful for the Administrations and the main stakeholders in general.

The same tools and frameworks applied to delineate the requirement are used to: i) assess the risks level for the pollution of the water courses and the graduation of the requirement; ii) inform the farmers of the necessity to be compliant to the requirement; iii) control the respect of the requirement at large scale, limiting the use of ground on-the-spot controls only in doubt or in negative cases.

\section{Materials and Methods}

Test activities were split in two phases. First of all a preliminary study aimed at defining the main characteristics to be analyzed was 
set up, such as: classification and segmentation criteria for water courses, auxiliary data and their importance for the integration of water streams vs. agro-environmental territory, risk definition.

This task, was realized though a Geomatic-GIS approach, on two sample areas in Emilia Romagna region, considering different morphological zones (plain and hilly).

The second phase concerns the planning and the GIS building, at large scale, on Marche Region (province of Macerata, Chienti river basin), through Remote Sensing and ancillary data, both available and to be created, such as: Ortho-photo AGEA, Digital Surface Model (DSM) $20 \mathrm{~m}$ and $2 \mathrm{~m}$ grid (Figure 1), Land Parcel Environmental System (LPIS) of Italy (Figure 2), large scale thematic mapping [litho, pedo; Available Water Content (AWC)], Meteo, protected areas (parks, SIC, ZVN, etc.), supported by a semi-automatic territorial classification of all local water basins, for the identification of the buffer geo-location of the strips areas (Figure 3).

The realized GIS is able to identify: i) where and on which agroenvironmental zones the standard must be applied (e.g. pastures and annual crops distinction for fertilization impact scenarios, etc.); ii) the hierarchical risk levels of the previously defined areas (different local water sheds through morphology, permeability, rainfall indexes, etc.); iii) the typology and size-range of the vegetation buffers to be applied, based on the calculated risk.

As additional test, an experimental interferometric SAR flight by AGEA-Telaer system, aiming at building a very large scale DSM for a comparison with the optical $2 \mathrm{~m}$ grid is also foreseen as further step.

The main project steps can be summarized as follows:

1. Test areas selection: Emilia-R, Marche, (in agreement with JRC and Marche Region - Soil Department;

2. Remote sensing optical and SAR data acquisition;

3. DSM $20 \mathrm{~m}$ acquisition and DSM $2 \mathrm{~m}$ creation on selected municipalities (Emilia-Romagna and Marche regions, Chienti river water shed) with slope and aspects production at parcel level;

4. Ancillary data acquisition and validation (lithology, pedology, hydrography, LPIS, agro statistics -AGRIT, 30 years meteorological historical data base, Natura 2000, Nitrate maps, etc.);

5 . Processing and homogenization of different formats and projections; GIS building with overlapping;

6. Agronomic and litho-pedo-morphologic data crossing, with territorial classification and photo-interpretation controls;

7. Hydrology analysis for regional and local water shed characterizations; application of formulas for potential pollution balance definition, through the following:

$$
\mathrm{A}=(1-\text { Kper (lit, V, C)) x Cli x M x Flev }
$$

in case of surface drainage and

$$
\mathrm{B}=(\text { Kper }(\text { Lit, } \mathrm{V}, \mathrm{C})) \times \mathrm{Cli} \times \mathrm{M} \times \mathrm{Flev}
$$

in case of under-soil percolation, where $\mathrm{K}$ is the coefficient of percolation (soil, vegetation and crops types), Cli is rainfall index, $M$ is morphology and Flev are fertilization levels.

The factors of the formulas allow to evaluate the different pollution's risk for different phenomena and the unknown factor of vegetation buffer to be created along water streams (note: A case appears more dangerous than B for water pollution speed and capacity, due to the faster runoff).

8. Drawing different vulnerability areas and risk definition at water shed level, with possible buffer classes (size) suggestion 9. DSM by Telaer interferometric SAR flight for operational comparisons (morphology, altitude, slopes, aspects)

10. Results and cost/benefit analysis, for a national extension of the applied test and the economic impact for farmers (additional work and loss of income)

11. General method to be proposed for a real shared European project.

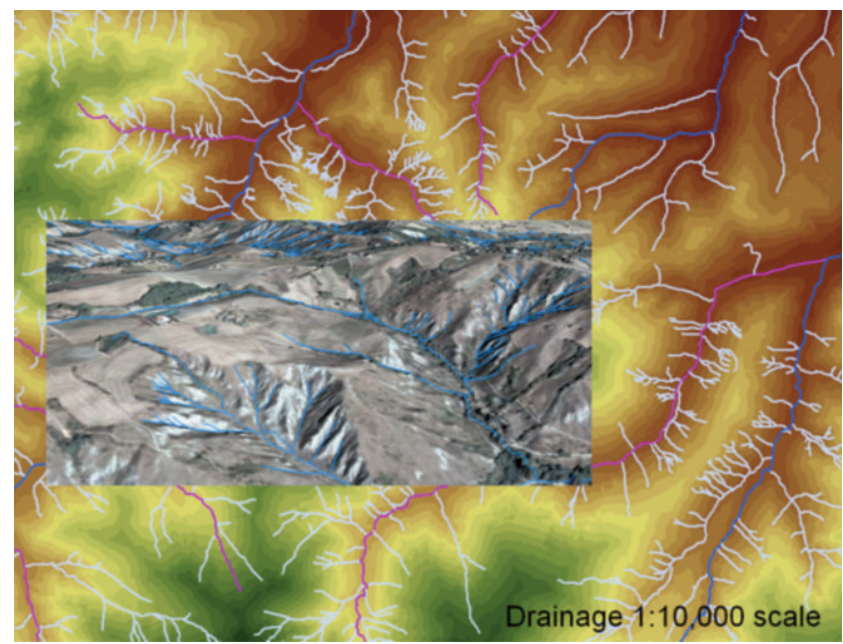

Figure 1. 3D accurate morphology by Digital Surface Model 2m, overlaid by hierarchical hydrology and ortho-imagery $0.5 \mathrm{~m}$.

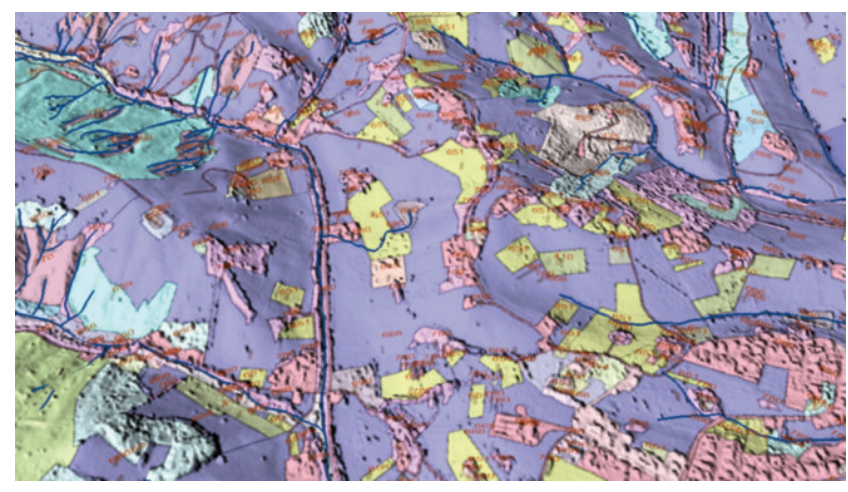

Figure 2. Digital Surface Model 2m, overlaid by hierarchical hydrology and Land Parcel Identification System (LPIS) for agroforestry characterization.

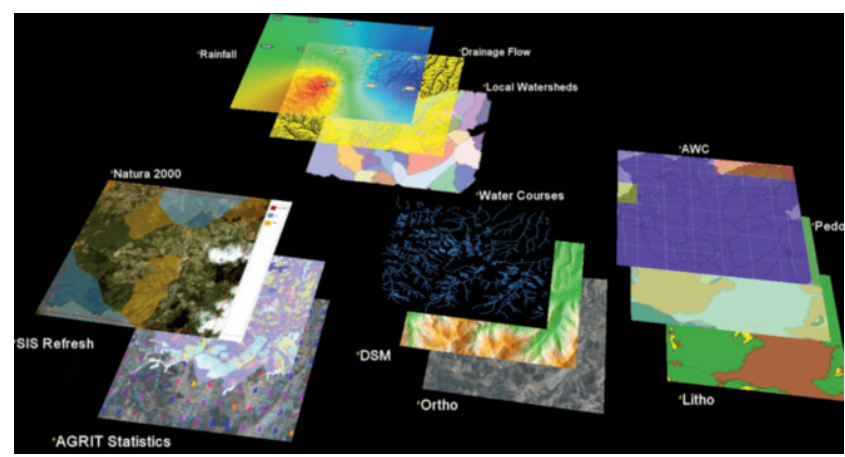

Figure 3. Example of a complete overview of the used thematic layers for the GIS generation, aimed at risk zones and water courses definition. Already existing data and layers result the main component of the activity, allowing a correct re-use of data and a better benefit /costs ratio. 


\section{Results}

The main test outputs (still in progress), can be summarized as follows:

- large amount of processed Remote Sensing and cartographic data, also at intermediate level for other environmenta/territorial uses and applications;

- technical reports and presentations on the methodology and the achieved results;

- thematic layers by crossing outputs, with risk areas geo-definition and buffer strips size suggestion within water sheds;

- indicators development for environmental and spatial temporal efficiency;

- operational scenario for national risk analysis, starting from vulnerability zones and including monitoring and controls to be applied in 2012 ;

- analysis of the connections between the effects of the application of the buffer strip standard and the other correlated GAECs.

\section{Main regulations for cross compliance}

Reg. EC 73/2009 - introducing cross compliance under the CAP for the first pillar

Reg. EC 1122/2009 - laying down rules to implement the Reg. EC
73/2009 in particular for cross compliance and the Integrated Administration and Control System (IACS)

Reg. EC 1698/2005 - rural development - second pillar of the CAP

Reg. EC 65/2011 - application of Reg. EC 1698/2005. The equivalent of 1122/2009 for the second pillar

\section{Main national legislation for cross compliance}

Italian Ministry Decree 30125/2009 - laying down national rules for the application of cross compliance in Italy

\section{References}

USDA-NRCS/USEPA, 2000. Conservation buffers to reduce pesticide losses. Available from: http://www.in.nrcs.usda.gov/technical/ agronomy/newconbuf.pdf

Ongley E.D., 1996. Control of water pollution from agriculture - FAO irrigation and drainage paper 55. Availabel from: http://www. fao.org/docrep/W2598E/W2598E00.htm.

Vianello M., Vischetti C., Scarponi L., Zanin G., 2005. Herbicide losses in runoff events from a field with a low slope: role of a vegetative filter strip. Chemosphere 61:717-25. 